\title{
ECOEMPREENDEDORISMO E COMPETÊNCIAS EMPREENDEDORAS: O CASO ECOEMPREENDEDOR TRANSFORMADOR DE RESÍDUO EM RIQUEZA
}

\author{
S. M. M. FONSECA ${ }^{1}$, A. P. SILVA ${ }^{\mathbf{1}^{*}}$, D. C. L. P. SANTOS ${ }^{\mathbf{2}}$ e E. F. LEITE ${ }^{1}$
${ }^{1}$ Universidade de Pernambuco
${ }^{2}$ Centro Federal de Educação Tecnológico-CEFET-RJ
andreapsil2@hotmail.com ${ }^{*}$ \\ Artigo submetido em setembro/2014 e aceito em abril/2015 \\ DOI: $10.15628 /$ holos.2015.2367
}

\section{RESUMO}

Este estudo visa evidenciar as competências empreendedoras mais presentes no ecoempreendedor que inova na criação de produto que destina corretamente os resíduos de óleo de fritura usado, transformando-os em riqueza, sobretudo por sua contribuição ao meio ambiente através da reciclagem, contribuindo diretamente para a promoção de uma sociedade sustentável. Vale salientar que as observações das características empreendedoras se deram sob a perspectiva das competências empreendedoras descritas por McClelland, além de enfoques do empreendedorismo em recente literatura. Nesse sentido, foi necessário um contato direto com o empreendedor, na sua empresa. Uma entrevista semiestruturada foi realizada com o empreendedor e os resultados apresentados foram obtidos através das informações oriundas da aplicação de um questionário respondido pelo mesmo. Através desse estudo de caso, chegou-se à conclusão que todas as competências foram identificadas, sobretudo busca de oportunidades, iniciativa e busca de informações.

PALAVRAS-CHAVE: Ecoempreendedorismo, Competências Empreendedoras, Reciclagem.

\section{ECOENTREPRENEURSHIP AND ENTREPRENEURIAL SKILLS: THE ECOENTREPRENEUR CASE TRANSFORMER WASTE IN WEALTH}

\begin{abstract}
This study aims to highlight the entrepreneurial skills more present in ecoentrepreneur that innovates in creating product that properly designed waste of used frying oil, turning them into wealth, particularly for his contribution to the environment through recycling, directly contributing to the promotion of a sustainable society. It is worth noting that the observation of entrepreneurial characteristics is given from the perspective of entrepreneurial skills described by McClelland, and entrepreneurial approaches in recent
\end{abstract}

literature. In this sense, it required a direct contact with the entrepreneur in his company. A semistructured interview was conducted with the entrepreneur and the results presented were obtained from information derived from the application of a questionnaire for the same. Through this case study, it was concluded that all skills that all competencies have been identified, mainly seeking opportunities, initiative and search for information.

KEYWORDS: Ecoentrepreneurship, Entrepreneurial Skills, Recycling. 


\section{INTRODUÇÃO}

A sociedade brasileira está cada vez mais percebendo a relevância da sustentabilidade, em função da crescente sensibilização à problemática ambiental. Uma pesquisa da Confederação Nacional da Indústria e do Instituto Brasileiro de Opinião e Estatísticas (CNI/IBOPE, 2010) relatou a expansiva preocupação dos brasileiros sobre o meio ambiente. Segundo esta pesquisa, o aquecimento global é o assunto que mais preocupa o brasileiro, com $27 \%$; $51 \%$ dos entrevistados disseram que pagariam mais por produtos ecologicamente corretos, entretanto, apenas $11 \%$ deles dão preferências a esses produtos na hora da compra.

As complexas demandas socioambientais induzem a um novo posicionamento das organizações (TACHIZAWA, 2011). Dessa maneira, ainda que os setores econômicos estejam focados na lucratividade, a sociedade vem exigindo dos empreendimentos, dos empresários e dos empreendedores a adoção de ações de caráter social e ambiental, que contribuam para a inclusão cidadã e preservação ambiental.

Binswanger (2002) afirma que se deve empreender uma reorientação da Teoria Econômica sob o paradigma da sustentabilidade, já que a natureza é fonte de recursos para produção e também fator de qualidade de vida. Consequentemente, os processos de transformação econômica e social exigem novos modelos de gerenciamento, assim como novos procedimentos, instrumentos e outras formas de ação capazes de criar condições adequadas para o desenvolvimento regional e global.

Em grande parte, a atividade empresarial provoca danos ao meio ambiente. É importante que a empresa conheça estes impactos e atue de forma a minimizar seus efeitos, como resposta à crescente vigilância da sociedade sobre as questões ambientais. A nova consciência ambiental emerge das transformações culturais que ocorreram nas décadas de 60 e 70, até meados da década de 1980; a maioria dos países criou leis ambientais ou tornou as existentes mais rígidas (DONAIRE, 1999; TACHIZAWA, 2011).

Para garantir o cumprimento da legislação, surgiram órgãos ambientais nos diversos níveis governamentais, o que implicou em um processo contínuo para construção de uma cidadania que restabelecesse o equilíbrio dinâmico da relação sociedade-natureza, o que inclui as empresas também. Essas mudanças têm ocorrido nas últimas décadas, desde a Conferência de Estocolmo, em 1972, ECO-92, em 1992, até a Conferência Rio+20, em 2012.

Nesse contexto, o empreendedorismo voltado para a promoção de uma cultura de sustentabilidade surge como uma alternativa eficaz para harmonizar as esferas econômica, ambiental e social (SANTOS et al., 2013). Discussões acerca do papel do empreendedor neste cenário têm chamado atenção de pesquisadores, acadêmicos e também dos próprios empreendedores. Afinal, quais competências são requeridas para os empreendedores que visam à harmonia dessas esferas, também conhecidos como ecoempreendedores?

Desta forma, este estudo visa evidenciar as competências empreendedoras mais presentes no ecoempreendedor que inova na criação de produto que destina corretamente os resíduos vegetais, transformando-os em riqueza. Vale salientar que as observações das características empreendedoras se deram sob a perspectiva das competências empreendedoras descritas por McClelland e também a recente literatura sobre empreendedorismo. 


\section{REFERENCIAL TEÓRICO}

\subsection{Empreendedorismo}

A realidade brasileira convive com a ausência de políticas duradoras direcionadas ao empreendedorismo e ações da iniciativa privada que proporcionem capital de risco (DORNELAS, 2008). Para superar os obstáculos de natureza política e econômica, o empreendedor recorre a sua capacidade criativa. Schumpeter apud Dornelas (2008) afirmava que:

O empreendedor é aquele que destrói a ordem econômica existente pela introdução de novos produtos e serviços pela criação de novas formas de organização ou pela exploração de novos recursos e materiais (Joseph Schumpeter, 1949 apud Dornelas, p.22, 2008).

Há o consenso que o empreendedorismo tende a provocar a reestruturação das economias nacionais desde o uso da tecnologia da informação ou simplesmente pela inovação nos processos da cadeia produtiva. Timmons (1994) propõe três fatores essenciais para existência do processo do empreendedor: o planejamento, por meio de um plano de negócio e identificação das oportunidades, depois alocar recursos necessários ao negócio e, por último, gerenciar o novo negócio sempre atento às mudanças do mercado.

Assim, o sucesso do empreendimento depende da habilidade do empreendedor para garantir o equilíbrio através da aplicação de criatividade e liderança, e de maneira integrada e holística. Pois, a natureza dinâmica da ação empreendedora exige proatividade, mas também exige paciência e perseverança (TIMMONS, 1994).

Diante da forte volatilidade entre oferta de empregos e candidatos, insere uma conjuntura propícia ao empreendedorismo de necessidade ou de oportunidade. Para o pleno desenvolvimento da atividade, é necessário planejamento, suporte governamental e ações da iniciativa privada a fim de proporcionar crédito para o desenvolvimento dos empreendedores. Dados do relatório Global Entrepreneurship Monitor sobre o empreendedorismo no Brasil - GEM (2013) mostram que os empreendedores brasileiros reafirmam a necessidade de melhoria de políticas governamentais, apoio financeiro, programas educacionais e capacitação. De acordo com a mesma pesquisa, cresce o empreendedorismo por oportunidade; no ano de 2013 foi de $71,3 \%$ e em 2002 era da ordem $42 \%$.

O empreendedorismo por oportunidade é aquele em que o empresário inicia uma atividade para melhorar sua condição de vida, uma atividade normalmente planejada, como recomenda Timmons (1994); já o por necessidade é aquele em que as pessoas empreendem para sobreviver. Aspecto positivo para economia é que os empreendimentos de oportunidade tendem a se estabelecer no mercado, pois possuem baixa taxa de mortalidade (GEM, 2013).

\subsubsection{Competências Empreendedoras e Perfil Empreendedor}

O conceito de competência está intrinsicamente relacionado com desenvolvimento do indivíduo. Segundo McClelland $(1972 ; 1987)$ é uma característica subjacente a uma pessoa que é casualmente relacionada com desempenho superior na realização de uma ação ou em determinada situação, entretanto, a competência diferencia-se de aptidões naturais da pessoa, mas pode vir a ser aprimorada. 
Para Nassif, Andreassi e Simões (2011) a competência:

[...] pode ser considerada como um último nível da característica de um indivíduo, abordando diferentes traços de personalidade, habilidades e conhecimentos, que partem das influências de experiências, treinamentos, educação, família e outras variáveis demográficas (NASSIF, ANDREASSI e SIMÕES, 2011, p.38).

De acordo com Man e Lau (2000), a competitividade na micro e pequena empresa (MPE) é fortemente influenciada pelas competências do empreendedor.

Filion (1999) aponta McClelland como o autor que efetivamente lançou as bases para a vertente comportamentalista das pesquisas em Empreendedorismo, além de demonstrar grande interesse no estudo da atividade dos gerentes de grandes corporações.

McClelland (1972) relaciona empreendedor à necessidade de sucesso, de reconhecimento, ao desejo de poder e de controle. Em suas pesquisas esse autor define necessidade de realização - vontade humana de se superar e de se distinguir, englobando um conjunto de características psicológicas e comportamentais que compreendem, entre outras, gosto pelo risco moderado, iniciativa e desejo de reconhecimento - como a principal força motivadora do comportamento empreendedor.

Mais tarde, McClelland (1987) constatou a necessidade de focar seus estudos nas características da competência empreendedora, a fim de estimular a ação empreendedora, pois tende a promover o desenvolvimento econômico de um empreendimento ou localidade. $O$ Quadro 1 demostra as dez características empreendedoras descritas por McClelland, em síntese elas configuram as principais atitudes que os empreendedores exteriorizam no desempenho das suas ações empreendedoras. Ou seja, são atributos importantes para o êxito dos empreendedores.

Quadro 1 - Características Empreendedoras

\begin{tabular}{|c|c|}
\hline \multicolumn{2}{|c|}{ Características } \\
\hline 1 & Independência e autoconfiança \\
\hline 2 & Persuasão e rede de contatos \\
\hline 3 & Planejamento e monitoramento sistemáticos \\
\hline 4 & Busca de informações \\
\hline 5 & Estabelecimento de metas \\
\hline 6 & Assunção de riscos calculados \\
\hline 7 & Exigência de qualidade e eficiência \\
\hline 8 & Comprometimento \\
\hline 9 & Persistência \\
\hline 10 & Busca de oportunidade e iniciativa \\
\hline
\end{tabular}

Fonte: Adaptado de McCLELLAND, p. 225-227, 1987.

Segundo Leite (2000), nas qualidades pessoais de um empreendedor, entre muitas, destacam-se: iniciativa, visão, coragem, firmeza, decisão, atitude de respeito humano e capacidade de organização e direção. Mamede e Moreira (2005) relatam que a competência empreendedora pode ser tratada tanto como competência do indivíduo, quanto relacionada à prática administrativa, devido às diferentes tarefas que desempenham. Isso quer dizer que as 
ações empreendedoras também estão associadas às competências por representarem o senso de identificação de oportunidades.

As referências mais antigas sobre o perfil do empreendedor foram concebidas pelo economista Joseph Schumpeter (1997), quando em 1911 publicou "A Teoria do Desenvolvimento Econômico". Além de colocar o empreendedor como a peça principal para que haja o desenvolvimento econômico, Schumpeter nos legou uma rica percepção psicológica das motivações e aptidões dos empreendedores. Para o autor, "[...] os empresários (empreendedores) são um tipo especial, e o seu comportamento um problema especial, a força motriz de um grande número de fenômenos significativos" (SCHUMPETER, 1997, p.88).

Schumpeter explica essa singularidade, ou super poderes dos empreendedores, cuja definição the rendeu a maior parte das críticas. Explica então que o que caracteriza o empreendedor é uma espécie distinta de conduta, uma característica destacada de outras pessoas.

O tipo de conduta em questão não apenas difere do outro em seu objetivo, sendo-lhe peculiar a 'inovação', mas também por pressupor aptidões que diferem em tipo, e não apenas em grau, daquelas do mero comportamento econômico racional (SCHUMPETER, 1997, p.90).

Schumpeter (1997) faz uma comparação com o canto. Todos podem cantar, entretanto, uns tem mais habilidade que outros.

\begin{abstract}
Embora praticamente todos os homens possam cantar, a habilidade para cantar não deixa de ser uma característica diferenciadora e um atributo de uma minoria, na verdade não exatamente de uma categoria, porque essa característica - diferentemente da nossa - afeta relativamente pouco o total da personalidade (SCHUMPETER, 1997, p.88).
\end{abstract}

Para Drucker (1986) o empreendedorismo é um comportamento e não um traço de personalidade e suas bases são o conceito e a teoria, não a intuição. Diferentemente de Peter Drucker (1986), Schumpeter (1997) nos apresenta um empreendedor intuitivo, que age quase que por adivinhação, impulsionado pelo desejo de conquistar, lutar, de fazer as coisas e de se realizar.

\title{
2.2 Ecoempreendedorismo
}

O ecoempreendedorismo sinaliza novas oportunidades e geração de novos postos de emprego. Trata-se de um movimento com empreendedores que criam negócios a partir de oportunidades, não necessariamente seus agentes estão imbuídos pela conscientização ambiental em prol da construção de um gerenciamento ecológico na economia.

O ecoempreendedorismo pode ser definido como a atividade empreendedora que intervém no campo da ecologia, em prol do meio ambiente. Essa atividade pode ser realizada tanto por uma empresa privada quanto por uma organização não-governamental sem fins lucrativos, ou até pelo governo, desde que inove com soluções que visem a melhoria do planeta sob os preceitos da ecologia. $O$ ecoempreendedor altera a ordem econômica com suas inovações e se destaca por utilizar novos insumos, como recursos de energias renováveis e materiais 
ecologicamente corretos. Mais que isso, o ecoempreendedor trabalha com valores, consciência e cultura ambiental (SANTOS et al., 2013).

Em linhas gerais, o empreendedorismo ambiental ou ecoempreendedorismo visa gerar valor ecológico e econômico através de inovações ambientalmente amigável (eco-friendly), ou seja, a partir da adoção de uma produção mais limpa e eficiente (SCHARPE, 2005; SCHALTEGGER e WAGNER 2011).

Para Schaltegger e Wagner (2011), o empreendedor ambiental ou ecoempreendedor é uma pessoa que objetiva contribuir para resolução da problemática ambiental e simultaneamente gera valor econômico, uma vez que ambos objetivos estão integrados ao negócio.

As motivações podem até divergir quanto ao que levou o empreendedor a tornar-se um ecoempreededor. Entretanto, o ecoempreededorismo atuará sob a perspectiva da sustentabilidade. Vale salientar que sustentabilidade é mais que ecologia, engloba fatores sociais, culturais, territoriais. Significa que o ecoempreendedor deve expressar o seu compromisso com a adoção e a difusão de valores, condutas e procedimentos que induzam e estimulem o desenvolvimento sustentável, ou seja, resultem em melhoria da qualidade de vida da sociedade e preservação do meio ambiente, convergente com a perenidade do negócio, através de estratégias de longo prazo.

Um novo mercado surge, novos produtos e serviços são desenvolvidos para atender a demanda de consumidores conscientes, e, consequentemente um novo empreendedor deve emergir para atender às mudanças que são exigidas atualmente. É nesse contexto que o ecoempreendedorismo se apresenta como ferramenta de transformação econômica, social, cultural, territorial e ambiental (SANTOS et al., 2013).

\section{PROCEDIMENTOS METOdOLÓGICOS}

A fim de analisar as competências empreendedoras de um empreendedor realmente inovador, buscou-se para esta pesquisa um empreendedor, proprietário de micro empresa, que tivesse inovado no reaproveitamento de resíduos sólidos e dado entrada em processo de patente de produto ou processo. Essas características se devem ao fato de que, empiricamente, o perfil de empresas desse porte que inovam (com finalidade na sustentabilidade) e buscam o registro é muito pequeno. Considerando isso, o empreendedor entrevistado foi indicado pelo SEBRAE/PE, que é uma instituição referência de apoio aos pequenos empreendedores.

Para a realização desta pesquisa, optou-se pelo método qualitativo. Foi realizada revisão do material bibliográfico a respeito dos temas relacionados a fim de embasar o estudo para verificar o comportamento empreendedor do empresário que contribuía ou desconstruía a ideia de ecoempreendedorismo.

Nesse sentido foi necessário um contato direto com o empreendedor, na sua empresa. Posteriormente uma entrevista semiestruturada foi realizada com o empresário e os resultados apresentados foram obtidos através das informações oriundas da aplicação de um questionário respondido pelo empreendedor. A entrevista ocorreu no mesmo local de trabalho do respondente e foi realizada pelos autores deste artigo. 
Essa entrevista foi gravada e transcrita na íntegra para o melhor aproveitamento de seu conteúdo e, assim, a organização das categorias de respostas. Terminada as transcrições, os dados foram tratados por meio da análise de conteúdo. Consoante com a proposta de Bardin (1977), os três procedimentos metodológicos da análise de conteúdo foram seguidos rigorosamente: a pré-análise, exploração do material e o tratamento dos resultados.

A análise de conteúdo também auxiliou na compreensão objetiva da fala do entrevistado, evitando a compreensão espontânea, intuitiva e livre por parte dos pesquisadores, ajudando a diminuir o risco de se gerar material com conteúdo superficial e de se realizar inferência desprovida de fundamentação lógica e estruturada.

A dificuldade para a realização desta pesquisa foi encontrar pessoas com o perfil desejado para responder ao problema de pesquisa e que tivessem disponibilidade para participar dela. A boa rede de contatos dos autores foi fundamental para a realização do estudo.

\section{RESULTADOS}

\subsection{Transformando Resíduo do Óleo Vegetal em Riqueza}

O rápido aumento populacional, o crescimento desordenado dos centros urbanos, o processo de industrialização e as mudanças socioeconômicas produzidas pelo capitalismo acarretaram na promoção de um estilo de vida consumista, que contribui no aumento da geração de resíduos sólidos e, principalmente, quanto à disposição e tratamento desse descarte. A problemática dos resíduos sólidos ficou relegada a um plano secundário de relevância nas agendas governamentais, o que acarretou em graves problemas urbanos, com um gerenciamento oneroso e complexo, concebendo graves problemas à saúde humana e à qualidade ambiental.

Em países desenvolvidos, a reciclagem de resíduos é setor lucrativo e necessário em virtude das restritivas legislações ambientais, deixando de ser resíduos e se transformando em riqueza. Entretanto, no Brasil, é ainda tímida, com exceção de alguns materiais. Todavia, torna-se um celeiro de oportunidades a empreendedores atentos.

O estudo do Instituto de Pesquisa Econômica e Aplicada (IPEA, 2010) estima que o país perca anualmente $\mathrm{R} \$ \mathbf{8}$ bilhões por enterrar materiais recicláveis que poderiam retornar à produção industrial. A reciclagem propicia vantagens: na preservação de recursos naturais; economia de energia; economia de transporte (pela redução de material que demanda o aterro); geração de emprego e renda; e sensibilização da população para as questões ambientais.

A Política Nacional de Resíduos Sólidos (PNRS), Lei no 12.305/2010, institui uma gestão integrada de resíduos sólidos, com responsabilidade compartilhada entre Estado, empresas e sociedade. Objetiva a redução da geração de resíduos sólidos e incentiva a reciclagem do lixo por meio de um manejo adequado. Em seu capítulo 2, art. 3 inciso XI, define gestão integrada de resíduos sólidos como sendo o conjunto de ações voltadas para a busca de soluções para os resíduos sólidos, de forma a considerar as dimensões política, econômica, ambiental, cultural e social, com controle social e sob a premissa do desenvolvimento sustentável.

Entretanto, ainda não há legislação específica quanto à questão do óleo de cozinha, por parte da União; apenas algumas legislações estaduais, entre elas a de Pernambuco, Lei no 14.378, 
de 2 de setembro de 2011, que em seu Art. 20 determina que "os bares, restaurantes, padarias, condomínios residenciais, sejam eles horizontais ou verticais, além de indústrias que utilizem do óleo vegetal comestível e demais estabelecimentos similares ficam obrigados a instalarem, em local visível e de acesso regular a clientes, funcionários ou moradores, um compartimento específico destinado a receber o descarte do óleo vegetal comestível a fim de propiciar seu recolhimento e destinação para reciclagem" (PERNAMBUCO, 2011).

Mas, desde a década de 1990, ações pioneiras e esparsas pelo país vêm atuando na reciclagem de óleo de fritura. Desta maneira, a reciclagem do óleo consolida-se como uma prática importante para sustentabilidade, seja atenuando o impacto ambiental gerado pelo seu descarte inadequado ou reduzindo os custos.

De acordo com o Plano de Gerenciamento Integrado do Resíduo Óleo de Cozinha (PGIROC, 2009), concebido pelo estado de Minas Gerais, o descarte indevido pode provocar danos socioambientais e econômicos significativos, como: incrustações nas tubulações por onde passa, pois se emulsifica com a matéria orgânica, formando crostas e retendo resíduos sólidos, podendo atrair vetores de doenças e causar mau cheiro; aumento das pressões internas das tubulações, causado pelas incrustações, podendo romper os dutos e contaminar o solo e o lençol freático, além de ser necessária a utilização de produtos tóxicos nocivos ao meio ambiente para a retirada dessas crostas.

Em contrapartida, o ciclo de vida deste produto possibilita que se torne matéria- prima para os mais variados fins. Algumas possibilidades que o óleo pode ser reutilizado para produção de: sabão e detergentes; glicerina; farinha básica para ração animal; lubrificantes; massa de vidraceiro; e biodiesel.

\subsection{Análise dos resultados}

No município de Paulista, Região Metropolitana do Grande Recife, localiza-se, em instalações modestas, o ecoempreendimento - uma microempresa que recicla óleo usado de cozinha para fabricação de antiferrugem vegetal, em atuação desde 2001. O produto desenvolvido pelo empresário é um composto, biodegradável (principal diferencial do lubrificante), de óleos vegetais e aditivos para proteção de chassi de veículo e partes metálicas de equipamentos em geral contra a oxidação e corrosão causada pela chuva, umidade, maresia e atmosfera.

Baseado nas características empreendedoras, descritas por McClelland (1987), o empresário tem as competências 'busca de oportunidades e iniciativa' e 'busca de informações' estão presentes. No período de 1998 a 2001, ele buscou informações para destinação correta e reutilização do óleo de fritura. Inicialmente seu intuito era descobrir um procedimento de limpeza para poder reutilizá-lo como óleo de fritura novamente. Então, buscou informações em bibliotecas, no Departamento de Nutrição da Universidade Federal de Pernambuco (UFPE), no qual conseguiu contato com uma pesquisadora de São Paulo, que Ihe informou não era possível reaproveitar o óleo para consumo humano em virtude que após a fritura, o resíduo adquire toxinas que são possíveis causadoras de câncer de estômago, entretanto poderia utilizá-lo como matéria-prima para outras finalidades.

Foi daí que surgiu a ideia da fabricação de um lubrificante vegetal, recordando que, quando adolescente, seu pai usava óleo de mamona no carro da família como antiferrugem. 
Para produzir uma resina antiferrugem para carros a partir do óleo de cozinha usado, teria que realizar testes laboratoriais que pudessem viabilizar sua produção. As perspectivas se tornaram realidade após uma consultoria do SEBRAE e posterior linha de subvenção de crédito desta mesma instituição, possibilitando realizar os testes de desenvolvimento do produto no Instituto Tecnológico de Pernambuco (ITEP). Após os testes, ficou provado que seu óleo poderia servir para proteger metais contra corrosão. Foi então que se iniciou a segunda etapa do projeto: produção em escala.

Tentar reproduzir os testes em sua residência, sem recursos, fez com que ele levasse meses até finalmente chegar a concepção do produto, que foi aprimorado com o feedback dos seus primeiros clientes. Isso demonstra sua 'exigência de qualidade e eficiência' a fim de que o produto chegasse a consistência que o cliente desejava, configurando outra característica empreendedora. Ele recorda que "no início, as pessoas relutavam em guardar o óleo usado, mas hoje temos uma rede estável de fornecedores. É engraçado notar como os papéis se inverteram. Antes as pessoas me ofereciam dinheiro para eu recolher o óleo, hoje elas me vendem".

O empresário se orgulha das palestras que profere sobre o seu empreendimento e a importância da conservação ambiental para as empresas do Pólo Industrial de Suape (PE), além dos certificados dos cursos de educação ambiental que ele frequentou oferecidos na Agência Pernambucana do Meio Ambiente.

O empreendedor influencia positivamente a comunidade na qual está inserida; o atendimento é feito por meio de projetos sociais e contribui para o desenvolvimento e bem estar local. Além de fortalecer a negociação com os fornecedores, ao incluir a responsabilidade social nas estratégias e planos, a empresa fideliza clientes, consolidando e reforçando a marca e imagem da empresa, e agrega valor ao produto. Essas atitudes reforçam a competência 'persuasão e redes de contato'. Além da dedicação e excelente ideia, ele contou com consultoria, financiamento e incubação da empresa. O fato de buscar as informações o levou a manter uma boa rede de contatos e, assim, fechar bons negócios.

Ele também coleciona empreendimentos que não deram certo, porém continuou tentando em ter seu próprio negócio. A empresa de reciclagem é seu empreendimento com maior tempo de duração. É perceptível sua 'persistência' como competência empreendedora.

Atualmente, com quatro funcionários, o empreendedor em análise recolhe 15 mil litros de óleo por mês em restaurantes, hotéis, condomínios e hospitais da região metropolitana do Recife. Ao todo, são quase 500 estabelecimentos que compõe sua rede fornecedora. Segundo ele, o crescimento da empresa acompanhou o aumento da preocupação da sociedade com as questões ambientais e também da legislação. A empresa é autorizada pela Agência Pernambucana do Meio Ambiente (CPRH) e pelo IBAMA, e anualmente deve renovar a licença na CPRH e a cada trimestre no IBAMA.

Seu pioneirismo e 'comprometimento' são atributos para o sucesso do empreendimento.

\footnotetext{
"Se o cara é empreendedor, ele trabalha 24 horas por dia. Meu telefone é ligado direto. De meia noite eu estou recebendo ligação. (...) Porque o restaurante é aberto a noite inteira, né verdade? Aí, naquela hora o cara lembrou e liga pra $\operatorname{mim}$. Nem se lembra que é meia noite ou uma hora da manhã. $E$, eu atendendo da mesma forma se ele tivesse ligado durante o dia. (...). Eu adoro o que faço. Por isso que dá certo".
} 
A empresa atua deixando uma bobona de 50 litros no estabelecimento e, quando cheio do resíduo do óleo, ele vai coletar e repor a bobona. Por este serviço não é cobrado nada, a fim de conscientizar e motivar o empresariado do setor alimentício da importância de sua participação no projeto de reciclagem, armazenando o óleo vegetal usado e cumprindo a legislação do Estado de Pernambuco, a partir de 2011. A empresa paga pelo resíduo e dá a opção do estabelecimento poder reverter o valor em doação para Hospital de Câncer de Pernambuco.

O empresário identificou como necessário para o crescimento deste segmento de negócio, a existência de um maior controle dos órgãos ambientais em Pernambuco na fiscalização para o cumprimento da Lei no 14.378/2011 e da limpeza das caixas de gordura, principalmente a disposição final do rejeito devido à atuação clandestina de empresas irregulares.

O fato de passar dois anos se dedicando a pesquisas até formalizar o negócio é um indicador de que o empreendedor 'assume riscos calculados'. Entretanto, conforme análise feita na entrevista, as competências empreendedoras menos presentes foram a 'determinação de metas' e o 'planejamento e monitoramento sistemático'. Mesmo assim, com entusiasmo, menciona que está desenvolvendo outros produtos com base no resíduo óleo de cozinha, demonstrando 'independência e autoconfiança' nos projetos futuros.

\section{CONSIDERAÇÕES FINAIS}

A postura de crescimento econômico a qualquer custo não é mais admissível, mesmo que seja ainda praticada. O real desenvolvimento ocorre apenas com mudanças que não lhe forem impostas, mas que emergem de dentro para a sociedade, com iniciativa própria, constituindo um processo contínuo de mudanças que proporcione ganhos qualitativos para a localidade.

A empresa analisada é uma referência de ecoempreendimento pelo fato do empresário ter um comportamento empreendedor bastante ativo e elencar como prioridade a sustentabilidade, não só como um meio, mas como fim. Diversas práticas sustentáveis nos processos da empresa foram percebidos, tais como: reciclagem de resíduos sólidos, reaproveitando os resíduos na produção; racionalização na utilização de recursos naturais; educação ambiental entre seus clientes, fornecedores e funcionários; disposição final ambientalmente adequada; e responsabilidade social através de parceria com Hospital de Câncer de Pernambuco.

Promover o ecoempreendedorismo não representa apenas fornecer linhas de crédito, que já são difíceis para qualquer segmentação empreendedora no Brasil. Mais do que isso, o ecoempreendedorismo na contemporaneidade torna-se requisito para impulsionar o desenvolvimento sustentável e parte do próprio indivíduo. As oportunidades estão latentes e cabe a ele investir tempo, esforço e recursos nesse projeto. Porém, cabe ao setor público investir em infraestrutura e, sobretudo, tecnologia. Como há poucos incentivos e subsídios para o desenvolvimento deste segmento de mercado, acaba por encarecer o valor do produto.

O fato de termos apenas uma empresa analisada nos leva a algumas conclusões: baixo interesse dos empreendedores em criar soluções sustentáveis inovadoras, falta de incentivo governamental e de educação ambiental. 
Este tipo de estudo é embrionário no Brasil; isso faz com que a academia busque mais informações a respeito do tema e se aproxime da realidade das micro e pequenas empresas, que correspondem a maior parcela (98\%) das empresas no país, como afirma o Relatório Agenda Estratégica das Micro e Pequenas Empresas de 2012, publicado pelo SEBRAE. Pesquisas futuras podem esclarecer se a inovação, na busca de oportunidades, realmente é a característica mais presente dos ecoempreendedores e que tipo de ambiente propício e indutor o país deve criar para que ecoempreendedores de pequenos negócios possam ser estimulados.

\section{REFERÊNCIAS BIBLIOGRÁFICAS}

1. BARDIN, L. Análise de conteúdo. Lisboa: Edições 70, 1977.

2. BINSWANGER, H. C. Fazendo a sustentabilidade funcionar. In: CAVALCANTI, Clóvis (org.) Meio ambiente, desenvolvimento sustentável e políticas públicas. 4a edição. São Paulo: Cortez, 2002.p.41-55.

3. BRASIL. Lei $\mathrm{N}^{\circ} 12.305$ de 02 de agosto de 2010. Institui a Política Nacional de Resíduos Sólidos; altera a Lei $\mathrm{n}^{\circ}$ 9.605, de 12 de fevereiro de 1998; e dá outras providências. Disponível em: <http://www.planalto.gov.br/ccivil_03/_ato20072010/2010/lei/l12305.htm>. Acesso em: 17 jun 2014.

4. CNI - IBOPE. Confederação Nacional da Indústria. Instituto Brasileiro de Opinião e Estatística. Retratos da sociedade brasileira: meio ambiente. Brasília: CNI, 2010.

5. DONAIRE, D. A Variável Ecológica no Ambiente dos Negócios. In: . Gestão Ambiental na Empresa. 2a ed. São Paulo: Atlas, 1999. cap. 2, p.28-38.

6. DORNELAS, J. C. A. O Processo Empreendedor. In: . Empreendedorismo Transformando Ideias em Negócios. 3a ed. Rio de Janeiro: Elsevier, 2008. cap. 2, p.05-36.

7. DRUCKER, Peter. Inovação e Espírito Empreendedor. São Paulo: Pioneira, 1986.

8. FILION, L. J. Diferenças entre sistemas gerenciais de empreendedores e operadores de pequenos negócios. Revista de Administração de Empresas, 39(4), 6-20, 1999.

9. GEM, Global Entrepreneurship Monitor. Empreendedorismo no Brasil: Relatório Executivo. Curitiba: Sebrae. Disponível em: < http://ois.sebrae.com.br/wp-content/uploads/2013/01/ Relatorio-Executivo-GEM-Brasil-2013.pdf >. Acesso em: 09 dez. 2014.

10. LEITE, E. O fenômeno do empreendedorismo: criando riquezas. Recife: Bagaço, 2000.

11. MAMEDE, M. I. de B.; MOREIRA, M. Z. Perfil de competências empreendedoras dos investidores Portugueses e Brasileiros: Um estudo comparativo na rede hoteleira do Ceará. In: ENANPAD: 2005. Anais... Brasília/DF.

12. MAN, T. W. Y.; LAU, T. Entrepreneurial competencies of SME owner/managers in the Hong Kong services sector: A qualitative analysis. Journal of Enterprising Culture, v. 8, n. 3, p. 235254, Sept. 2000.

13. MCCLELLAND, D. C. A sociedade competitiva: realização e progresso social. Rio de Janeiro: Ed. Expressão e Cultura, 1972.

14. Characteristics of successful entrepreneurs. The Journal of Creative Behavior, 21(3), 219-233, 1987. 
15. NASSIF, V. M.; ANDREASSI, T.; SIMÕES, F. Competências empreendedoras: Há diferenças entre empreendedores e intraempreendedores? Revista de Administração e Inovação, São Paulo, v. 8, n. 3, p.33-54, jul./set . 2011.

16. SANTOS, D. C. L. P; LEITE, E. F.; SILVA, C. M.; FONSECA, S. M. M. Empreendedorismo Sustentável: Perfil dos Produtores da Feira Agroecológica da Orla de Olinda - PE. HOLOS-ISSN 1807-1600, v. 2, 2013.

17. PERNAMBUCO. Lei $N^{\circ} 14.378$ de 02 de setembro de 2011. Institui a divulgação e instalação de recipientes coletores para a Reciclagem do Óleo Vegetal Comestível no Estado de Pernambuco, e dá outras providências; Disponível em: <http:// legis.alepe.pe.gov.br/arquivoTexto.aspx?tiponorma $=1 \&$ numero $=14378 \&$ complemento $=0 \& a$ no=2011\&tipo=>. Acesso em: 16 jun 2014.

18. SCHALTEGgER, S., WAGNER, Marcus. Sustainable Entrepreneurship and Sustainability Innovation: Categories and Interactions, Business Strategy and the Environment, 20, p. 222237, 2011.

19. SCHAPER, Michael. Understanding Green Entrepreneur. In: SCHAPER, M. (editor). Making Ecopreneur: Developing Sustainable Entrepreneurship. Hampshire: Ashgate, p. 3 - 12, 2005.

20. SCHUMPETER, Joseph A. Teoria do Desenvolvimento Econômico. Tradução: Maria Sílvia Possas. Rio de Janeiro: Editora Nova Cultural, 1997.

21. TACHIZAWA, T. Gestão Ambiental e Responsabilidade Social Corporativa: Estratégias de Negócios Focadas na Realidade Brasileira. 7ạ ed. São Paulo: Atlas, 2011.

22. TIMMONS, Jeffry A. New venture creation: entrepreneurship for the 21st century. Boston: Irwin McGraw-Hill, 4th. ed., 1994. 